\title{
Toward a High-Resolution Monitoring of Continental Surface Water Extent and Dynamics, at Global Scale: from GIEMS (Global Inundation Extent from Multi- Satellites) to SWOT (Surface Water Ocean Topography)
}

\author{
Catherine Prigent $^{1} \cdot$ Dennis P. Lettenmaier ${ }^{2}$ - Filipe Aires ${ }^{1,3}$ • \\ Fabrice Papa ${ }^{4,5}$
}

Received: 24 April 2015/Accepted: 28 August 2015/Published online: 12 October 2015

(C) The Author(s) 2015. This article is published with open access at Springerlink.com

\begin{abstract}
Up to now, high-resolution mapping of surface water extent from satellites has only been available for a few regions, over limited time periods. The extension of the temporal and spatial coverage was difficult, due to the limitation of the remote sensing technique [e.g., the interaction of the radiation with vegetation or cloud for visible observations or the temporal sampling with the synthetic aperture radar (SAR)]. The advantages and the limitations of the various satellite techniques are reviewed. The need to have a global and consistent estimate of the water surfaces over long time periods triggered the development of a multi-satellite methodology to obtain consistent surface water all over the globe, regardless of the environments. The Global Inundation Extent from Multisatellites (GIEMS) combines the complementary strengths of satellite observations from the visible to the microwave, to produce a low-resolution monthly dataset $\left(0.25^{\circ} \times 0.25^{\circ}\right)$ of surface water extent and dynamics. Downscaling algorithms are now developed and applied to GIEMS, using high-spatial-resolution information from visible, near-infrared, and synthetic aperture radar (SAR) satellite images, or from digital elevation models. Preliminary products are available down to 500-m spatial resolution. This work bridges the gaps and prepares for the future NASA/CNES Surface Water Ocean Topography (SWOT) mission to be launched in 2020. SWOT will delineate surface water extent estimates and their water storage with an unprecedented spatial resolution and accuracy, thanks to a SAR
\end{abstract}

Catherine Prigent

catherine.prigent@obspm.fr

1 CNRS, Laboratoire d'Etude du Rayonnement et de la Matière en Astrophysique et Atmosphères (LERMA), Observatoire de Paris, 61, avenue de l'Observatoire, 75014 Paris, France

2 Department of Geography, University of California, 1255 Bunche Hall, Box 951524, Los Angeles, CA 90095, USA

3 Estellus, 93, Boulevard de Sébastopol, 75002 Paris, France

4 Laboratoire d'Etude en Géophysique et Océanographie Spatiales, IRD, 18, avenue Edouard Belin, 31401 Toulouse, France

5 Indo-French Cell for Water Sciences, IRD-IISc Joint International Laboratory, Indian Institute of Science, C V Raman Ave, Bangaluru, Karnataka 560012, India 
in an interferometry mode. When available, the SWOT data will be adopted to downscale GIEMS, to produce a long time series of water surfaces at global scale, consistent with the SWOT observations.

Keywords Satellite remote sensing · Wetland · Hydrology

\section{Introduction}

Terrestrial surface waters amount to less than $1 \%$ of the total Earth water and cover less than $6 \%$ of the ice-free continents at any time (Shiklomanov 1993). However, they are the source of most $(\sim 2 / 3)$ of water consumed by humans (UN-Water 2007) and have a large impact on the biodiversity and on the biogeochemical and hydrological cycles, along with a key role on the climate variability. Continental surface waters encompass a very large variety of environments and circumstances, from exceptionally flooded populated areas and their related human loss, to strategic rice paddies to feed the populations, tropical wetlands very rich in biodiversity, or climate-sensitive boreal peat land with their large methane emission. The definition of wetlands varies according to research foci, and no overall consensus on the subject exists.

Despite their importance, there is a lack of reliable, continuous, and consistent information on the inundation extent and dynamics, at both global and regional scales, to satisfy a large and diverse community of users. Mapping of surface waters involves a wide range of users, practitioners, and stakeholders. These include water and disaster managers, insurance companies, hydrologists, ecologists, weather forecasters, or climate modelers. Some applications require high spatial resolution and temporal sampling with almost real-time observations, and others will favor global low spatial resolution with long-term objectives.

The potential role of satellite Earth observations for the mapping of surface waters has been stressed on many occasions, for different applications (e.g., Committee on Earth Observation Satellites 2013; Global Earth Observations 2013; Convention on Biological Diversity 2014). There are ongoing efforts to promote the satellite Earth observations for surface water mapping in these fields (e.g., the Global Monitoring of Environment and Security project DISASTER or the European Space Agency project GlobWetland I-III), but all user needs are still far from being satisfied.

Current satellite remote sensing techniques can produce seamless global land cover maps and distinguish many terrestrial environments, but still struggle to generate accurate high-spatial-resolution representations of surface water extents. There is some agreement on the surface area of the permanent open water bodies from satellite. With approximately $60 \%$ of the floodplains and wetlands inundated during only some time of the year, the knowledge of the extent and large variability of the land surface waters at regional-toglobal scales is still incomplete, even with the satellite observations.

The US-French Surface Water and Ocean Topography (SWOT) mission, to be launched in 2020, will provide the community with high spatial resolution and temporal sampling of the continental surface waters, thanks to a synthetic aperture radar (SAR) in an interferometry mode. However, what can be done meanwhile, with the current satellite observations, to support user needs and prepare for the SWOT mission?

We will first briefly review the satellite observation techniques that are commonly used to estimate the continental surface waters, including the advantages and limitation of each 
technique (Sect. 2). Some examples will be given. The need to have a global and consistent estimate of the water surfaces over long time periods triggered the development of a multisatellite methodology to obtain consistent surface water all over the globe, regardless of the environments. This method, first developed at low spatial resolution $(\sim 25 \mathrm{~km})$, is now downscaled down to $100 \mathrm{~m}$, for a consistent estimation of the surface water extent across spatial scales. These efforts will be described in Sect. 3. The potential of the SWOT mission to map the surface water will be presented in Sect. 4. We will conclude on the interest in the combination of the multiple sources of surface water estimates (Sect. 5).

\section{The Potential and Limitation of Satellite Techniques for Surface Water Estimation}

The detection and quantification of surface water extent from satellite sensors rely on the differences between the reflection and emission properties of water and land surfaces, due to differences in the refractive index of the medium or/and in its surface state (roughness/ flatness). Remote sensing techniques employing visible, infrared, and microwave observations offer varying degrees of success in detecting the wetland extent and in quantifying its dynamics. Some recent examples of visible and near-infrared estimates are presented, as well as passive and active microwave results.

Table 1 summarizes the different satellite techniques to map water surfaces, along with their key characteristics.

\subsection{Visible (VIS) and Near-Infrared (NIR) Observations}

Optical and near-infrared satellite observations provide good spatial resolution but are limited by their inability to penetrate clouds and dense vegetation.

Using the NOAA advanced very-high-resolution radiometer (AVHRR), inundated surfaces in herbaceous environments have been estimated with a $\sim 1 \mathrm{~km}$ resolution, such as in the Okavango delta (McCarthy et al. 2005) or in the Brahmaputra region (Jain et al. 2006). Since the advent of the moderate-resolution imaging spectroradiometer (MODIS) observations, it is possible to monitor continental-scale inundated areas with a 250- to 500-m spatial resolution, with freely and globally available data. Bergé-Nguyen and Crétaux (2015) showed the potential of MODIS data to monitor temporal changes in flooding in semiarid regions such as the Inner Niger Delta. Xiao et al. (2005, 2006) analyzed paddy fields in China by identifying the flooded pixels from the difference between the Land Surface Water Index (LSWI) and Vegetation Indexes (NDVI or EVI).

Table 1 Satellite techniques to map water surfaces and their main characteristics

\begin{tabular}{|c|c|c|c|c|}
\hline Technique & $\begin{array}{l}\text { Spatial } \\
\text { resolution }\end{array}$ & Temporal sampling & Contamination & Remarks \\
\hline VIS/NIR & $\begin{array}{l}\text { Down to } \\
\quad \sim 30 \mathrm{~m}\end{array}$ & $\begin{array}{l}\text { Down to daily if } \\
\text { cloud free }\end{array}$ & Clouds, vegetation & $\begin{array}{l}\text { Open water only at } \\
\text { global scale }\end{array}$ \\
\hline Active microwave SAR & $\begin{array}{l}\text { Down to } \\
\quad \sim 20 \mathrm{~m}\end{array}$ & $\begin{array}{l}\text { Up to } 6 \text { days with } \\
\text { Sentinel } 1\end{array}$ & $\begin{array}{l}\text { Vegetation to some } \\
\text { extent }\end{array}$ & $\begin{array}{l}\text { Regional applications } \\
\text { mostly so far }\end{array}$ \\
\hline Passive microwave & $\sim 10 \mathrm{~km}$ & Daily & $\begin{array}{l}\text { Vegetation to some } \\
\text { extent }\end{array}$ & $\begin{array}{l}\text { Detection of open water } \\
\text { as well as wetlands }\end{array}$ \\
\hline
\end{tabular}


Sakamoto et al. (2007) described the multi-year surface hydrology in the Mekong Delta using the MODIS reflectances. They develop a wavelet-based filter to limit the impact of the cloud cover during the monsoon season.

Nakaegawa (2012) compared water-related cover types in six 1-km global land cover datasets. They include the Global Lakes and Wetlands Database (GLWD) (Lehner and Doll 2004) based essentially on inventories and five estimates from visible imagery such as a MODIS classification and a SPOT-derived estimate. The global total open water areas are similar for all datasets. However, the agreement is mediocre for wetlands, with the visible and near-infrared satellite estimate of the total wetland surface of the order of 10 times lower than the GLWD surface. There is only a $5 \%$ chance that a wetland pixel in GLWD corresponds to one in the other five datasets. This is partly due to the difficulty of detecting water under a vegetation canopy and to the period of reference selected in the different datasets. It is noted that the GLWD can be considered to be the best 1-km global static water-related land cover dataset currently available.

We tested two MODIS-derived wetland detection methods over the Mekong Delta region, based on the work of Sakamoto et al. (2007) and Bergé-Nguyen and Crétaux (2015) (Fig. 1). With the Sakamoto et al. (2007) method, we tested two cloud filters. The water extents at the maximum are comparable, with similar seasonality. However, the estimates show significant differences, especially for the detection of the mixed pixels. The methods are quite sensitive to the different thresholds adopted in the algorithms, and their sensitivity to cloud is critical to the results.

A water detection methodology initially developed for MODIS has recently been applied to the entire Landsat archive over 30 years at 30-m resolution, exploiting the processing power of the Google Earth Engine platform (Pekel et al. 2015). A global validation exercise showed an accuracy of $90 \%$ with respect to local estimates. Changes in lakes, river courses, and dams are documented, as well as coastal modifications. The potential of the methodology for open water detection appears very attractive, but it has not been evaluated yet for wetland characterization.

The method is sensor-neutral and can be applied to other optical instruments. The Sentinel 2 mission is designed to provide a global coverage of the Earth's land surface every 10 days with one satellite and 5 days with two satellites. The first satellite has been launched recently (June 2015). Among many other objectives, Sentinel 2 will contribute to the mapping of water surfaces. It is expected that methods already developed for MODIS and Landsat will be applied to the observations, with possible adaptation to the Sentinel 2 specificities.

\subsection{Active Microwave Observations}

Synthetic aperture radar (SAR) and altimeters are active microwave instruments that measure the backscattering coefficient of observed surfaces. Microwaves have the ability to penetrate clouds and, to a certain extent, vegetation. When observed off-nadir (as with the SAR), open water surfaces are characterized by low backscattering coefficients. The presence of vegetation can scatter the signal and increase the backscattering, making the detection of wetland site specific. The longer the wavelength, the less sensitive it is to the presence of vegetation. The SAR observations can provide very high spatial resolution (below $50 \mathrm{~m}$ ), but until recently the spatiotemporal coverage was limited, with only a few mosaics available per year in some areas, preventing systematic, long-term assessments of inundation dynamics. The ENVISAT SAR instrument, for instance, operated between 2002 and 2012 and imaged the Earth with a large swath at $\mathrm{C}$ band $(5.3 \mathrm{GHz})$. For the 

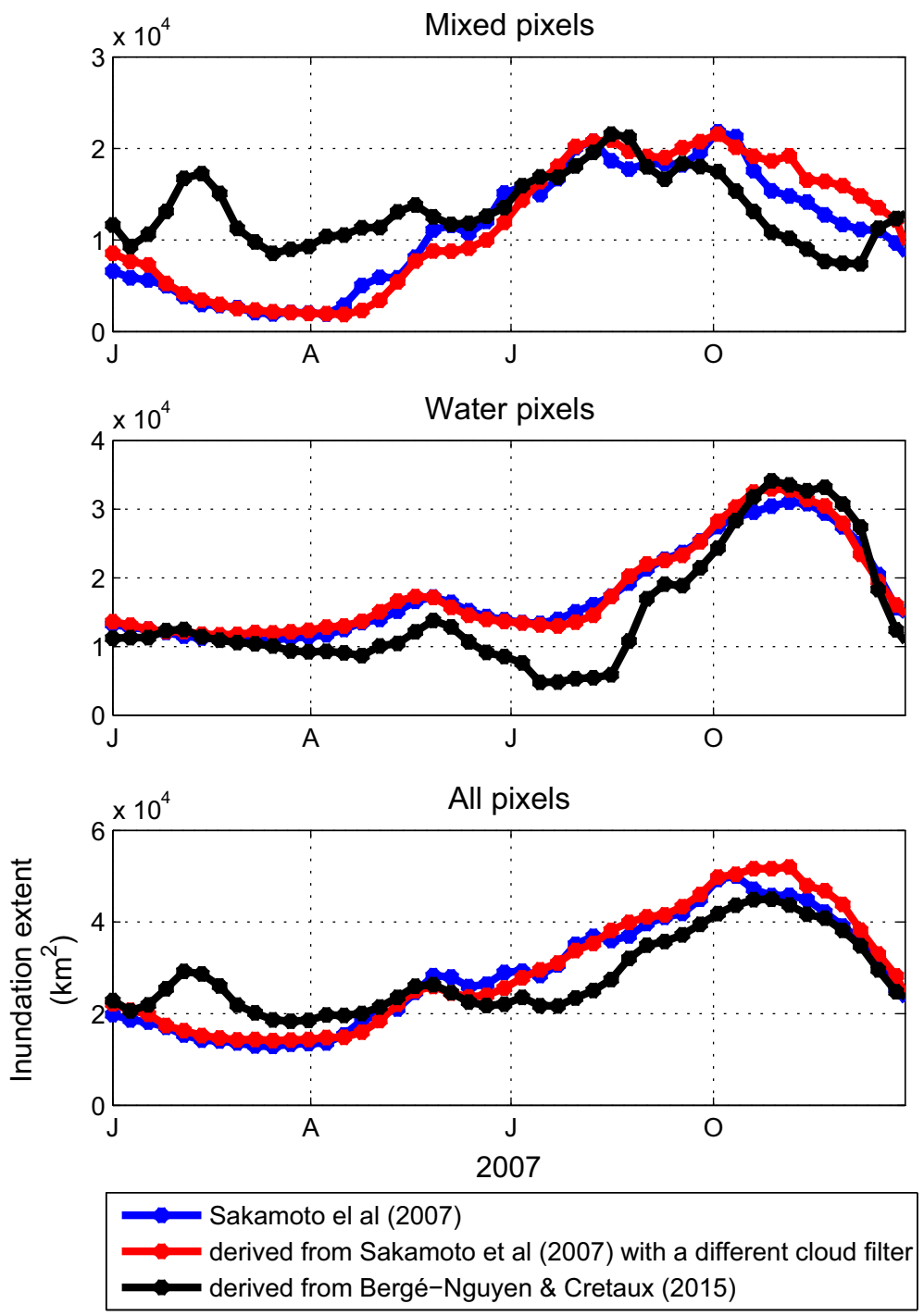

Fig. 1 Inundation extent over the Mekong Delta, as estimated by different methods, on a monthly mean basis, for 2007

northernmost latitudes, almost daily observations were available, but some other areas were hardly covered such as South America or Australia.

Henderson and Lewis (2008) reviewed the literature on the detection of wetland ecosystems with SAR, including the optimum wavelength and polarization. A large range of observation configurations and analysis methodologies have been tested, with different efficiencies depending on the type of environment. They conclude that it is difficult to select a unique methodology for systematic global application and that a combination with visible / near-infrared observations is always very efficient. 
Using long-wavelength SAR observations (L-band, $1.4 \mathrm{GHz}$ ), Hess et al. (2003) produced detailed maps of the low and high water stages in the Amazon basin, despite the dense tropical forest. With ENVISAT SAR data, Bartsch et al. (2012) detected the open water dynamics at high latitudes, but showed difficulties in delineating the vegetated wetlands. Kuenzer et al. (2013) derived inundated images of the Mekong basin for 20072011 from ENVISAT SAR, with a spatial resolution of $\sim 90 \mathrm{~m}$. The inundation cycle is described, thanks to a reasonable revisit time in the region over several years. A preprocessing step filters the image and reduces the speckle. Then, a series of thresholds is carefully applied on the backscatter to isolate the water surfaces, before applying a morphological image processing. Bouvet and Toan (2011) analyzed the rice paddies in South Asia with success, using ENVISAT SAR observations.

The extensive archive of ENVISAT SAR images has not been analyzed much for largescale water mapping. Nevertheless, a global map of permanent and open water bodies has been obtained recently by Santoro and Wegmuller (2014), exploiting the temporal variability of the observations. At least 10 images are required for a reliable estimate, which is not always obtained over the ENVISAT SAR life time (Santoro and Wegmuller 2014). There is no evaluation yet of this method for wetland mapping, at global scale.

Similar techniques are currently adjusted to be applied to the recently launched Sentinel 1 SAR (April 2015). Sentinel 1 will provide an improved coverage and temporal sampling, especially over Europe. The mission will image the entire Earth every six days when the two satellites have been launched. With the most promising methods to detect water surface based on the temporal variability of the signal, the high temporal sampling of the Sentinel SAR is expected to revolutionize the mapping of water surfaces with high spatial resolution, high temporal sampling, even under cloudy regions.

Satellite altimeters are also active microwave instruments. They observe at nadir to measure surface topography and were originally designed for ocean surfaces. Techniques have been developed to obtain accurate measurements of water height in rivers, lakes, and wetlands from these satellite-borne instruments (e.g., Birkett 1998; Fu and Cazenave 2001). Altimeters are very sensitive to the presence of water, with a significant increase in the backscattering over water surfaces (Papa et al. 2003). However, current altimeters have very narrow surface tracks and do not provide sufficient spatial coverage to analyze the horizontal structure of water bodies, except over boreal regions where their polar orbits offer better spatial coverage. Papa et al. (2006) quantified the extent and seasonality of boreal inundation using observations from the Topex-Poseidon dual-frequency satellite altimeter and evidenced the high potential of the altimeters for surface extent estimations.

\subsection{Passive Microwave Observations}

Passive microwave observations have long been used to detect surface water extents (e.g., Giddings and Choudhury 1989). Inundation decreases emissivity in both linear polarizations, especially at lower frequencies, due to differences in dielectric properties of water and soil or vegetation. In addition, inundation can also increase the polarization difference with the roughness change related to the presence of water. However, the spatial resolution of current passive microwave observations is of the order of $10-50 \mathrm{~km}$, limiting their potential use for a large range of applications.

Most passive microwave studies are based solely on simple analyses of the raw passive microwave observations. The study of the Amazon basin by Sippel et al. (1998) or the analysis of the boreal regions by Mialon et al. (2005) is one such example, at regional scale. Schroeder et al. (2010) also rely mainly on the passive microwave observations from 
AMSR-E to estimate the North Eurasian inundation dynamics. However, the passive microwave signal is strongly modulated by the surface temperature and, above $10 \mathrm{GHz}$, it can be contaminated by the atmosphere (water vapor), clouds, and rain. These factors, especially surface temperature, can seriously distort time-series estimates of surface water variations.

\section{A Multi-satellite Methodology for Global Surface Water Estimation}

These considerations lead to the conclusion that there is not today a unique and exclusive technique for detecting surface water, including open water and wetlands. A multi-satellite technique has been derived for the retrieval of surface water extent and dynamics at the global scale. It capitalizes on the complementary strengths of the satellite observations to extract maximum information about inundation characteristics and to minimize problems related to analysis of measurements by one instrument only (Prigent et al. 2001, 2007, 2012; Papa et al. 2010).

\subsection{The Global Inundation Extent from Multi-satellites (GIEMS)}

Satellite data have different sensitivities to surface properties (e.g., vegetation, topography, and soil properties), making it possible to disentangle the contributions of the various factors on the observations. Passive microwave observations are particularly sensitive to the presence of the surface water, even under vegetation canopy, and the inundation detection will primarily rely on the passive microwave signal. Passive microwave observations have limited spatial resolution (of the order of $20 \mathrm{~km}$, depending on the frequency), but can provide frequent global coverage over a long time period (more than 20 consistent years of data available).

The following satellite observations are used: (1) passive microwaves from the special sensor microwave/imager (SSM/I) measurements between 19 and $85 \mathrm{GHz}$; (2) active microwave backscattering coefficients at $5.25 \mathrm{GHz}$ from scatterometers; and (3) visible and near-infrared reflectances and the derived NDVI. Preprocessing is applied to the passive microwave observations to suppress the modulation by the surface temperature and by the atmospheric effects. In vegetated areas, the vegetation contribution to the passive microwave is estimated with information from the active microwave and NDVI observations. An unsupervised clustering algorithm merges the three sets of satellite observations and identifies the inundated pixels. A mixture model based on the statistical relationship between the passive polarization differences and the active microwave backscatter quantifies the fractional inundation of each pixel identified in the previous step. The technique is globally applicable without tuning for specific environments. The availability and reliability of the active microwaves and the visible/near-infrared observations imposed some fine-tuning of the initial methodology (details are provided in Papa et al. 2010).

Fifteen years of global monthly water surface extents 1993-2007 are available, on an equal-area grid of $0.25^{\circ} \times 0.25^{\circ}$ at the equator (each pixel covers $773 \mathrm{~km}^{2}$ ) (http://lerma. obspm.fr/spip.php?article91\&lang=en). Figure 2 shows the averaged yearly maximum inundation from GIEMS, from 1993 to 2007. The water surfaces are realistically detected under all environments. See the boreal floodplains around the $\mathrm{Ob}$ or the Yenisei, the Inner Niger Delta in Mali, or the Pantanal and riverine wetlands along the Amazon in South 


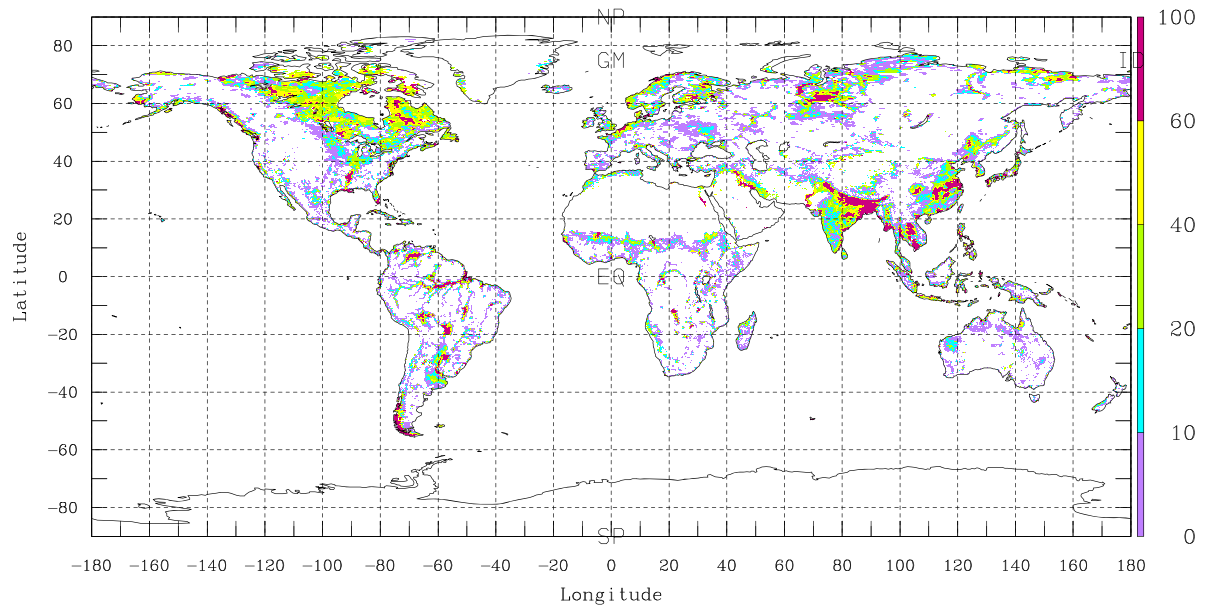

Fig. 2 The averaged yearly maximum inundation at the global scale from GIEMS, in terms of percentage of inundation for each pixel, from 1993 to 2007 . Each pixel is $773 \mathrm{~km}^{2}$

America. Note that the GIEMS estimates include all surface waters such as the Asian rice paddies, as well as river and lakes.

GIEMS, with its long time series, provides key information on the seasonal and interannual variability of the inundation, even at regional scale. As an example, a major flood occurred in the American Midwest, along the Mississippi and Missouri rivers and their tributaries, from April to October 1993, causing terrible devastation and flooding up to $80,000 \mathrm{~km}^{2}$. Figure 3 presents the mean surface water extent in August over the Midwest in the USA between 1993 and 2007 (top), as compared to its value in August 1993 (bottom). The maximum inundated surface in the region calculated by GIEMS is very close to the official number, and its spatial pattern follows closely the expected hydrological structures.

Regional assessment of this database using SAR data indicates that the approach realistically captures wetland complexes but can underestimate small wetlands comprising less than $10 \%$ fractional coverage of a grid cell $\left(<80 \mathrm{~km}^{2}\right)$. The dataset has been extensively evaluated at the global scale (Prigent et al. 2007; Papa et al. 2010) and for a wide range of environments, including boreal (Papa et al. 2007, 2008) and tropical regions (Papa et al. 2006; Frappart et al. 2008).

The availability of this consistent and carefully evaluated dataset at a global scale and over a long period of time makes it possible to perform climatological analysis. We observed a decline of the wetland extent of $\sim 6 \%$ over the globe between 1993 and 2008. The largest declines of open water are found where large increases in population have occurred over the last two decades, suggesting a global scale effect of human activities on continental surface freshwater (Prigent et al. 2012).

GIEMS has also been used for biogeochemical and hydrological analyses, such as the evaluation of methane surface emissions models (Bousquet et al. 2006; Ringeval et al. 2010; Melton et al. 2013; Wania et al. 2013) and the validation of the river flooding schemes coupled with land surface models (Decharme et al. 2008, 2011; Ringeval 2012; Pedinotti et al. 2012). 

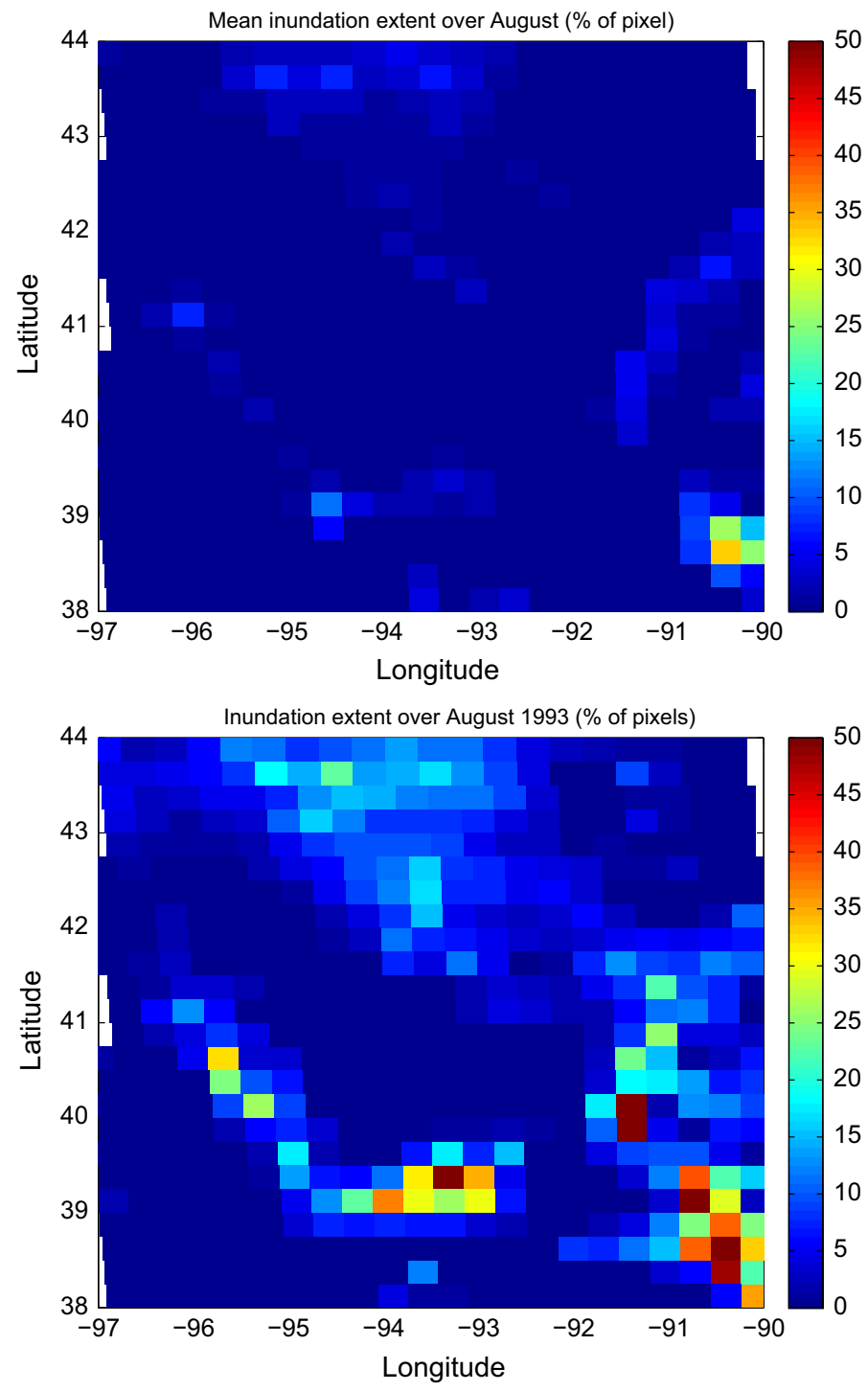

Fig. 3 Mean surface water extent in August over the Midwest in the USA between 1993 and 2007 (top), and its value in August 1993 (bottom)

\subsection{Downscaling of GIEMS}

With a $0.25^{\circ} \times 0.25^{\circ}$ spatial resolution, the initial GIEMS dataset is clearly not adequate for all applications. Would it be possible to develop downscaling methodologies to derive high-resolution surface water extent from the existing GIEMS low-resolution dataset? Since GIEMS has global coverage, the ideal situation would be to develop a downscaling technique general enough to work in all environments. However, each hydrological basin has its own characteristics such as its topography, vegetation, or space-time variability. 
The downscaling algorithm needs to take into account these specificities and the availability of the a priori high-spatial-resolution information for a particular basin. The highspatial-resolution information can come from satellite observations such as visible /nearinfrared images or SAR measurements, or it can be extracted from static topography information. Methodologies have been explored, using these different types of high-spatial-resolution sources. They are described here.

\subsubsection{Downscaling Based on High-Resolution Satellite Observations}

Two downscaling methodologies based on high-resolution satellite observations have been developed and evaluated, with very encouraging results. These two methods require inundation information at high spatial resolution, at least for some time steps, in coincidence with the coarse spatial resolution dataset.

The first methodology is based on image processing techniques and can be applied with a limited number of high-spatial-resolution information (Aires et al. 2013). It has been applied and evaluated over the Amazon basin, using the SAR-derived observations of Hess et al. (2003) to calibrate the method, at only two time steps, for low and high waters. The probability of a high-spatial-resolution pixel to be inundated depends on the status of its neighboring pixels, and this probability is derived from the SAR images. The inundation then fluctuates between the low and high water stages for each month, based on the GIEMS monthly dynamics, using a dilatation factor driven by the inundation probability. Following this methodology, 15 years of monthly mean inundation extent for the Amazon basin have been produced at 500-m spatial resolution (Aires et al. 2013). Figure 4 shows an example of the downscaling of GIEMS with the SAR observations, over the Amazon
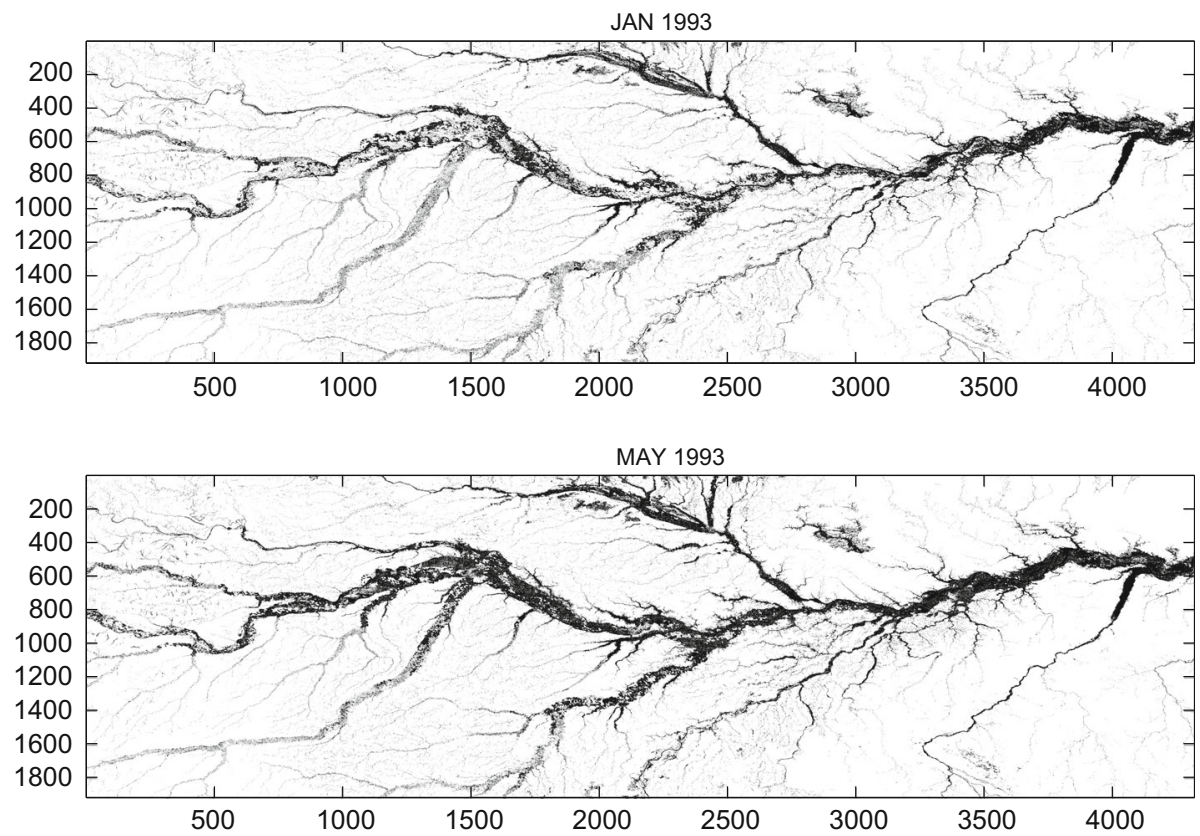

Fig. 4 Inundation extent from the downscaling of GIEMS, for two contrasted months in 1993, over the Amazon Basin 
basin, in 1993, from two contrasted months. The hydrological structures are very realistic: The results benefit from the spatial structure of the SAR data coupled to the temporal dynamics of GIEMS. With the advent of the recently available Sentinel 1 SAR data, it is expected to have soon a global coverage of the inundated surfaces derived from the highresolution observations, at different periods of the year at global scale. The downscaling method will be trained on this SAR-derived dataset and propagated backward in time, as for the Amazon case.

The second solution requires the availability of more information on the dynamics of the inundation at high resolution. It uses the empirical orthogonal function (EOF) representation of the space-time variability of the high-resolution inundation extent, and to be efficient, a reasonable representation of the inundation dynamics has to be provided over a year. It has been applied to the Inner Niger Delta, using MODIS-derived inundation extent (Bergé-Nguyen and Crétaux 2015), to produce a long time series (1993-2011) of highresolution inundation extent. This technique makes possible not only the downscaling of low-spatial-resolution information but also the temporal and spatial interpolation of highresolution dataset (Aires et al. 2014).

\subsubsection{Downscaling Based on Topography Information}

Topography information at high spatial resolution can also provide the basic information to derive an inundation probability to determine from GIEMS where inundation is spatially more likely at high resolution. Digital elevation models (DEM) can describe the topography with the necessary accuracy at a global scale, making this methodology globally applicable.

Fluet-Chouinard et al. (2015) adopt the Shuttle radar topography mission (SRTM)derived HydroSHED topographic information trained on a global land cover map (GLC2000 Bartholomé and Belward 2005) to produce an inundation probability map based only on topography information. The downscaled inundation map is then generated from the inundation probability map by distributing the inundated area of the coarse pixels among the fine-resolution pixels having the highest probabilities of inundation. The technique is applied to GIEMS to produce a 15 arc-s $(\sim 500 \mathrm{~m})$ map of the mean annual minimum, mean annual maximum, and long-term maximum (GIEMS-D15). Comparison with independent regional maps shows reasonable agreement, with some variation depending on the environments. This database is available under request at http://www. estellus.fr/index.php?static13/giems-d15. Work is underway to produce a monthly mean dynamic dataset at $90-\mathrm{m}$ resolution from GIEMS.

\section{The Future with SWOT}

As noted above, the altimeter observations are very sensitive to the presence of water, but their current ability to see freshwater bodies is severely limited by the fact that all present and past altimeters are nadir pointing, that is, they produce information only for the water surfaces that their thin track crosses. This has the effect that water bodies with surface areas less than about $10 \mathrm{~km}^{2}$ generally are not resolvable by nadir altimeters (Biancamaria et al. 2015). Furthermore, it is difficult to obtain estimates of the temporal variations of water bodies much smaller than this threshold.

The joint US-French Surface Water and Ocean Topography (SWOT) mission is intended to provide a major improvement in the availability of surface extent and storage 
change for surface bodies such as lakes, reservoirs, wetlands, and rivers. The revolutionary aspect of SWOT compared to former altimeters is that it will provide swath, rather than track, data; hence, the size of water bodies for which surface and storage change estimates can be retrieved is dictated by factors other than the distance between altimeter satellite tracks. SWOT's primary instrument will be a Ka-band radar interferometer (KaRIn), which is a SAR interferometer in the Ka-band $(37 \mathrm{GHz}$ ), with near nadir incidence angles (between $0.6^{\circ}$ and $3.9^{\circ}$, Fjrtoft et al. 2014). SWOT will provide images of water surface and elevation in swaths on both sides of the satellite track, each of which will be $50 \mathrm{~km}$ wide. Because interferometry effectively involves a triangulation, each point in the swath will be observed from two different (antenna) positions, which will allow precise estimation of the location of each point. More details of SAR interferometry and the KaRIn measurements are provided by Biancamaria et al. (2015) and references therein. KaRIn will provide images of water surface elevations for pixels with sizes $\sim 6 \mathrm{~m}$ in the direction of the satellite orbit and from 10 to $60 \mathrm{~m}$ in the direction perpendicular to the satellite orbit (the smallest dimension is for pixels far off-nadir in the swath; the largest dimension is for those closest to nadir). The instrument concept is presented in Fig. 5.

SWOT will extract a dynamic water surface mask (i.e., that identifies open water as contrasted with other land cover) for each satellite overpass. The SWOT Science Requirements Document (Rodríguez 2015) indicates that the SWOT requirement is to estimate surface water areas for water bodies larger than $250 \mathrm{~m}^{2}$ to an accuracy (one standard deviation) of better than $15 \%$, and the goal is for one standard deviation error for smaller water bodies (between 100 and $250 \mathrm{~m}^{2}$ ) of no more than $25 \%$. The SWOT pixel size is expected to be from 50 to $300 \mathrm{~m}^{2}$. The requirement and goal are based on discretization errors presuming adequate radiometric contrast between land and water pixels. Fjrtoft et al. (2014) show that the contrast at the SWOT KaRIn instrument frequency can

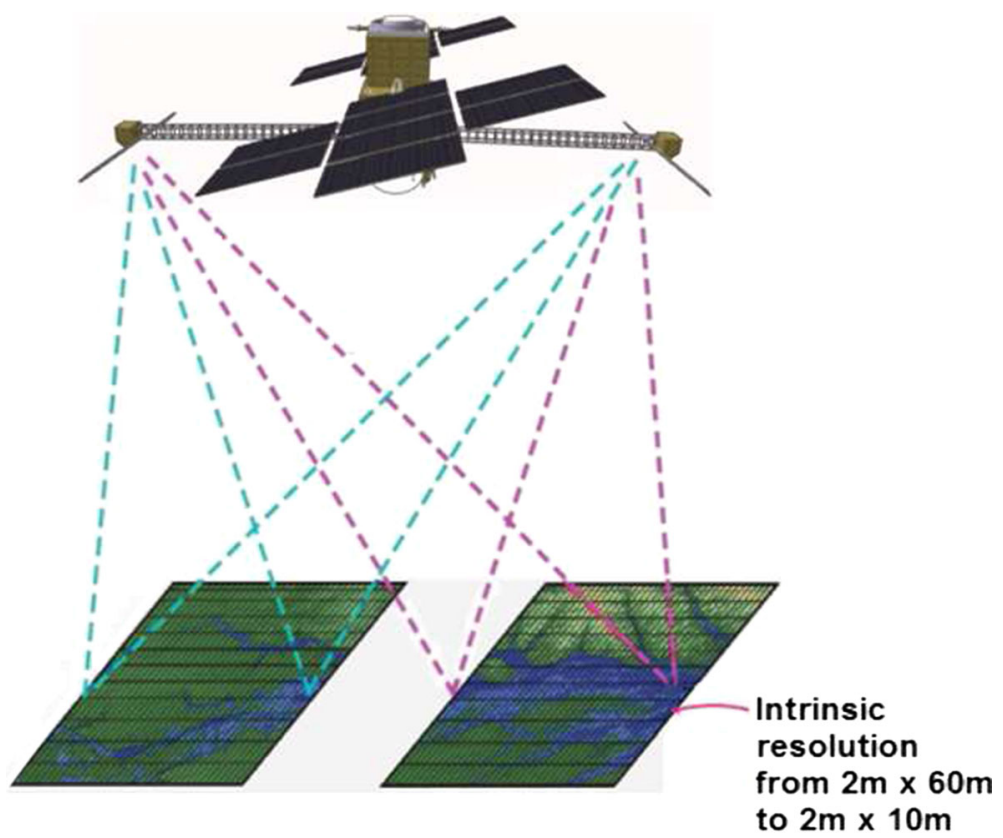

Fig. 5 SWOT instrument concept. Courtesy of Lee et al. (2010) 
be as high as $20 \mathrm{~dB}$. However, they also point out that the ability to discriminate between land and water pixels is complicated for the KaRIn instrument by the fact that its incidence angle $\left(0.6^{\circ}-3.9^{\circ}\right)$ is small relative to most existing SARs and Ka-band has backscatter characteristics at small incidence angles that are not well documented. They further note that the layover effect at these small incidence angles (which occurs when the slope of surrounding topography exceeds the incidence angle) are prevalent at much smaller surface slopes than for larger incidence angles. However, layover is mitigated by the backscatter contrast between water and surrounding topography, and this in turn is affected by surface roughness and other factors. The combined effect of these various factors is not well understood at this point; however, ongoing testing with an aircraft version of the KaRIn instrument is expected to much better define these interactions.

The water surface elevation estimates for these pixels are approximately statistically independent with error standard deviations of around $1 \mathrm{~m}$; hence, errors are reduced (by averaging) by approximately $1 /$ sqrt(n), where $n$ is the number of pixels. Accordingly, by averaging the number of pixels in a water body of area $1 \mathrm{~km}^{2}$, the vertical error estimates become less than $10 \mathrm{~cm}$ (see Fu et al. 2012 for details). The actual error budget of course is much more complicated (due to other sources of errors, like the effects of surrounding topography and wet tropospheric delay), but the goal of SWOT is to obtain vertical errors less than $10 \mathrm{~cm}$ for water bodies with areas greater than $1 \mathrm{~km}^{2}$ (Rodríguez 2015).

Lee et al. (2010) in a study of Arctic lakes estimated that SWOT surface extent errors should be less than about $5 \%$ for lakes with surface areas greater than $1 \mathrm{~km}^{2}$ and less than about $20 \%$ for lakes with surface areas of 1 ha. Downing et al. (2006) estimated that there are about 300 million lakes globally with surface area exceeding $0.001 \mathrm{~km}^{2}$, of which $99.87 \%$ in number and $43 \%$ in area have surface areas less than $1 \mathrm{~km}^{2}$. Verpoorter et al. (2014) estimated about 117 million lakes with surface areas that exceed $0.002 \mathrm{~km}^{2}$, most of which have areas between 0.1 and $1 \mathrm{~km}^{2}$. Both studies have important caveats, and there remains considerable uncertainty as to the distribution of lakes at the global scale. Based on Downing et al. (2006) and other estimates, Biancamaria et al. (2015) concluded that SWOT should be able to see the dynamics of surface area and height for a total of about $65 \%$ of global lake storage globally. The approximately $1 / 3$ that will not be seen will mostly be in small lakes and ponds with surface areas less than about 6 ha. One should keep in mind that there are certain caveats, not all of which are considered in any but the most recent studies. For instance, the ability to recover storage change in some lakes will be compromised by layover effects, which essentially result from confounding of the surface elevation retrieval with surrounding topography. This is mostly a potential problem in topographically complex regions (e.g., mountains), and there are in fact some opportunities for mitigating this issue, at least for larger lakes. Furthermore, there are other aspects of the SWOT error budget that continue to be studied and will likely affect the above estimates.

The current generation of nadir altimeters, along with visible band instruments such as MODIS with overpass intervals short enough to produce time series of surface extent, only sees about $15 \%$ of total lake surface and storage. Increasing this number to around $65 \%$ represents a huge improvement. 


\section{Conclusions and Perspective}

Up to now, high-resolution mapping of surface water extent from satellites has only been available for a few regions, over limited time periods. The extension of the temporal and spatial coverage of these maps was not possible, due to the lack of necessary satellite observations (e.g., poor time sampling for the SAR), or to physical limitation of the remote sensing technique (e.g., the interaction of the radiation with vegetation or cloud for visible observations).

Satellite-derived maps of open water bodies at high spatial resolution are now emerging, over long time series, with the systematic processing of a large volume of satellite data [e.g., Pekel et al. (2015) with Landsat or Santoro and Wegmuller (2014) with the ENVISAT SAR]. However, these estimates only cover open water bodies and exclude the wetlands, despite their interest for a large range of environmental applications.

GIEMS provides the only global monthly surface water extent database, thoroughly evaluated and available over a long period of time (15 years). Its extension in time up to the present is underway. GIEMS comprises all surface waters, including open water, wetlands, or rice paddies. Its original spatial resolution is $\sim 25 \mathrm{~km}$, but downscaling methodologies have been developed to provide the user community with down to $100-\mathrm{m}$ resolution estimates. Some methods involve the use of high-spatial-resolution satellite data from visible/infrared observations or from SAR measurements, to train the downscaling algorithms. Other methods require topography information from digital elevation models. A first version of GIEMS at 500-m spatial resolution is available, based on this methodology (GIEMS-D15). Work is underway to produce a 90-m spatial resolution data base, with a monthly mean temporal resolution.

The downscaling of GIEMS provides a global consistent reference dataset on water surfaces, at high spatial resolution. It can complement the local independent current estimates, with a reference that is suitable at large scale, for applications such as risk management or pricing of insurance policies.

The advent of the SWOT mission will be transformational for the hydrology field, with its capacity to delineate surface water extent (lakes, rivers, wetlands during seasons of inundation, and reservoirs) and to estimate their water storage with an unprecedented spatial resolution and accuracy.

To provide the scientific community with a very long time record of surface water extent with a high spatial resolution and accuracy, the SWOT data, when available, can be adopted to downscale GIEMS over a common period of observations. The downscaling methodology trained on the SWOT dataset can then be applied back in time to produce a long time series of water surfaces at global scale, with a high spatial resolution, and consistent with the SWOT database. This will provide the hydrology and climate communities with an exceptional database that will be continuously extended in time during the SWOT lifetime.

Acknowledgments We are grateful to Bill Rossow and Elaine Matthews for their involvement at the origin of the work on GIEMS. We like to thank Etienne Fluet-Chouinard and Bernhard Lehner for their contribution to the GIEMS downscaling. We are also grateful to Sylvain Biancamaria for providing details for the SWOT description and to Pham Duc Binh for the comparisons of the surface water extents over the Mekong Delta. The downscaling of GIEMS has been partly financed by CNES, in the framework of the SWOT mission preparation, with the support of Selma Cherchali and Jean-Francois Crétaux.

Open Access This article is distributed under the terms of the Creative Commons Attribution 4.0 International License (http://creativecommons.org/licenses/by/4.0/), which permits unrestricted use, distribution, 
and reproduction in any medium, provided you give appropriate credit to the original author(s) and the source, provide a link to the Creative Commons license, and indicate if changes were made.

\section{References}

Aires F, Papa F, Prigent C (2013) A long-term, high-resolution wetland dataset over the Amazon basin, downscaled from a multi-wavelength retrieval using SAR. J Hydrometeorol 14:594-6007

Aires F, Papa F, Prigent C, Crétaux JF, Bergé-Nguyen M (2014) Characterization and downscaling of the inundation extent over the Inner Niger delta using a multi-wavelength retrievals and Modis data. J Hydrometeorol 27:1958-1979. doi:10.1175/JCLI-D-13-00161.1

Bartsch A, Trofaier A, Hayman G, Sabel D, Schlaffer S, Clark D, Blyth E (2012) Detection of open water dynamics with ENVISAT ASAR in support of land surface modelling at high latitudes. Biogeosciences 9:703-714. doi:10.5194/bg-9-703-2012

Bartholomé E, Belward AS (2005) GLC2000: a new approach to global land cover mapping from earth observation data. Int J Remote Sens 26:1959-1977

Bergé-Nguyen M, Crétaux J-F (2015) Inundations in the inner Niger delta: monitoring and analysis using MODIS and global precipitation datasets. Remote Sens. doi:10.3390/rs70x000x

Biancamaria S, Lettenmaier DP, Pavelsky TM (2015) The SWOT mission and capabilities for land hydrology. Surv Geophys (in press)

Birkett CM (1998) Contribution of the TOPEX NASA radar altimeter to the global monitoring of large rivers and wetlands. Water Resour Res 34. doi:10.1029/98WR00124

Bouvet A, Le Toan T (2011) Use of ENVISAT/ASAR wide-swath data for timely rice fields mapping in the Mekong River delta. Remote Sens Environ 115(4):1090-1101. doi:10.1016/j.rse.2010.12.014

Bousquet $\mathrm{P}$ et al (2006) Contribution of anthropogenic and natural sources to atmospheric methane variability. Nature 443:439-443. doi:10.1038/nature05132

Committee on Earth Observation Satellites (CEOS) (2013) Ad-hoc Disasters Team, CEOS disaster risk management observation strategy, Issue 2.1

Convention on Biological Diversity (2014) Earth Observation for biodiversity monitoring: a review of current approaches and future opportunities for tracking progress towards the Aichi Biodiversity Targets, CBD Technical Series No. 72. http://www.cbd.int/doc/publications/cbd-ts-72-en

Decharme B, Douville H, Prigent C, Papa F, Aires F (2008) A new river flooding scheme for global climate applications: offline validation over South America. J Geophys Res 113:D11110. doi:10.1029/ 2007JD009376

Decharme B, Alkama R, Papa F, Faroux S, Douville, Prigent C (2011) Global off-line evaluation of the ISBA-TRIP flood model. Clim Dyn 38:1389-1412. doi:10.1007/s00382-011-1054-9

Downing JA, Prairie YT, Cole JJ, Duarte CM, Tranvik LJ, Striegl RG, McDowell WH, Kortelainen P, Caraco NF, Melack JM, Middelburg JJ (2006) The global abundance and size distribution of lakes, ponds, and impoundments. Limnol Oceanogr 51(5):2388-2397. doi:10.4319/lo.2006.51.5.2388

Fjrtoft R, Gaudin JM, Pourthié N, Lalaurie JC, Mallet A, Nouvel JF, Martinot-Lagarde J, Oriot H, Borderies P, Ruiz C, Daniel D (2014) KaRIn on SWOT: characteristics of near-nadir Ka-band interferometric SAR imagery. IEEE Trans Geosci Remote Sens 52(4):2172-2185. doi:10.1109/TGRS.2013.2258402

Fluet-Chouinard E, Lehner B, Rebelo L-M, Papa F, Hamilton SK (2015) Development of a global inundation map at high spatial resolution from topographic downscaling of coarse-scale remote sensing data. Rem Sens Environ 158:348-361

Frappart F, Papa F, Famiglietti SJ, Prigent C, Rossow WB, Seyler F (2008) Interannual variations of river water storage from a multiple satellite approach: a case study for the Rio Negro River basin. J Geophys Res 113. doi:10.1029/2007JD009438

Fu LL, Cazenave A (2001) Satellite altimetry and earth science. A handbook of techniques and application. Academic Press, London

Fu LL, Alsdorf DE, Morrow R, Rodríguez E, Mognard NM (2012) SWOT: the surface water and ocean topography mission. JPL publication 12-05

Giddings L, Choudhury BJ (1989) Observation of hydrological feature with Nimbus-7 $37 \mathrm{GHz}$ data applied to South America. Int J Remote Sens 10:1673-1686

Global Earth Observations (2013) The GEOSS water strategy, from observations to decision, executive summary and full report. ftp://ftp.earthobservations.org/TEMP/Water/

Henderson FM, Lewis AJ (2008) Radar detection of wetland ecosystems: a review. Int J Remote Sens 29(20):5809-5835. doi:10.1080/01431160801958405 
Hess LL, Melack JM, Novob EMLM, Barbosac CCF, Gastil M (2003) Dualseason mapping of wetland inundation and vegetation for the central Amazon basin. Remote Sens Environ 87:404-428

Jain SK, Saraf AK, Goswami A, Ahmad T (2006) Flood inundation mapping using NOAA AVHRR data. Water Resour Manag 20(6):949-959

Kuenzer C, Gue H, Huth J, Leinenkugel P, Li X, Cech S (2013) Flood mapping and flood dynamic of the Mekong delta: ENVISAT ASAR- WSM based time series analyses. Remote Sens 5:687-715. doi:10. 3390/rs5020687

Lee H, Durand MT, Jung HC, Alsdorf D, Shum CK, Sheng Y (2010) Characterization of surface water storage changes in Arctic lakes using simulated SWOT measurements. Int J Remote Sens 31(14):3931-3953. doi:10.1080/01431161.2010.483494

Lehner B, Doll P (2004) Development and validation of a global database of lakes, reservoirs and wetlands. J Hydrol 296:1-22

Melton JR et al (2013) Present state of global wetland extent and wetland methane modelling: conclusions from a model inter- comparison project (WETCHIMP). Biogeosciences 10:753-788. doi:10.5194/bg10-753-2013

Mialon A, Royer A, Fily M (2005) Wetland seasonal dynamics and interannual variability over northern high latitudes derived from microwave satellite data. J Geophys Res 110. doi:10.1029/2004JD005697

McCarthy J, Gumbricht T, McCarthy TS (2005) Ecoregion classification in the Okavango Delta, Botswana from multitemporal remote sensing. Int J Remote Sens 26:43394357

Nakaegawa T (2012) Comparison of water-related land cover types in six 1-km global land cover dataset. J Hydro Meteorol. doi:10.1175/JHM-D-10-05036.1

Papa F, Legresy B, Remy F (2003) Use of the Topex-Poseidon dual-frequency radar altimeter over land surfaces. Remote Sens Environ 87:136-147. doi:10.1016/S0034-4257(03)00136-6

Papa F, Prigent C, Rossow WB, Legresy B, Remy F (2006a) Inundated wetland dynamics over boreal regions from remote sensing: the use of TopexPoseidon dualfrequency radar altimeter observations. Int J Remote Sens 27:4847-4866. doi:10.1080/01431160600675887

Papa F, Prigent C, Durand F, Rossow WB (2006b) Wetland dynamics using a suite of satellite observations: a case study of application and evaluation for the Indian Subcontinent. Geophys Res Lett 33:L08401. doi:10.1029/2006GL025767

Papa F, Prigent C, Rossow WB (2007) Ob River flood inundations from satellite observations: a relationship with winter snow parameters and river runoff. J Geophys Res 112. doi:10.1029/2007JD008451

Papa F, Prigent C, Rossow WB (2008) Monitoring flood and discharge variations in the large Siberian Rivers from a multi-satellite technique. Surv Geophys. doi:10.1007/s10712-008-9036-0

Papa F, Prigent C, Jimenez C, Aires T, Rossow WB (2010) Interannual variability of surface water extent at global scale, 1993-2004. J Geophys Res 115. doi:10.1029/2009JD012674

Pekel JF, Cottam A, Gorelick N, Belward A (2015) 30 Years global scale mappingof surface water dynamics at $30 \mathrm{~m}$ resolution. Mapping water bodies from space conference Frascati Italy. http://www.conftool. pro/mwbs2015/sessions.php

Pedinotti V, Boone A, Decharme B, Cretaux JF, Mognard N, Panthou G, Papa F, Tanimoun BA (2012) Evaluation of the ISBA-TRIP continental hydrologic system over the Niger basin using in situ and satellite derived datasets. Hydrol Earth Syst Sci 16:1745-1773. doi:10.5194/hess-16-1745-2012

Prigent C, Matthews E, Aires F, Rossow WB (2001) Remote sensing of global wetland dynamics with multiple satellite data sets. Geophys Res Lett 28:4631-4634

Prigent C, Papa F, Aires F, Rossow WB, Matthews E (2007) Global inundation dynamics inferred from multiple satellite observations. J Geophys Res 1993-2000:112. doi:10.1029/2006JD00784

Prigent C, Papa F, Aires F, Jimenez C, Rossow WB, Matthews E (2012) Changes in land surface water dynamics since the 1990s and relation to population pressure. Geophys Res Lett 39:5. doi:10.1029/ 2012GL051276

Ringeval B, de NobletDucoudré N, Ciais P, Bousquet P, Prigent P, Papa F, Rossow WB (2010) An attempt to quantify the impact of changes in wetland extent on methane emissions on the seasonal and interannual time scales. Global Biogeochem Cycles 24:GB2003. doi:10.1029/2008GB003354

Ringeval B et al (2012) Modelling subgrid wetland in the ORCHIDEE global land surface model: evaluation against rive discharges and remotely sensed data. Geosci Model Dev Discuss 5:683-735

Rodríguez E (2015) Surface water and ocean topography mission (SWOT), science requirements document. JPL document D-61923. JPL D-61923, Feb. 12, 2015, retrieved from https://swot.jpl.nasa.gov/files/ swot/SRD021215 Aug 24, (2015)

Sakamoto T, Nguyen NV, Kotera A, Ohno H, Ishitsuka N, Yokozawa M (2007) Detecting temporal changes in the extent of annual flooding within the Cambodia and the Vietnamese Mekong delta from MoDIS time-series imagery. Remote Sens Environ 109:295-313 
Santoro M, Wegmuller U (2014) Multi-temporal synthetic aperture radar metrics applied to map open water bodies. IEEE J Sel Top Appl Earth Obs Remote Sens 7:3225-3238. doi:10.1109/JSTARS.2013. 2289301

Sippel SJ, Hamilton SK, Melack JM, Novo EMM (1998) Passive microwave observations of inundation area and the area/stage relation in the Amazon river floodplain. Int J Remote Sens 19:3055-3074

Schroeder R, Rawlins MA, McDonald KC, Podest E, Zimmermann R, Kueppers M (2010) Satellite microwave remote sensing of North Eurasian inundation dynamics: development of coarse-resolution products and comparison with high-resolution synthetic aperture radar data. Environ Res Lett 5:015003. doi:10.1088/1748-9326/5/1/015003

Shiklomanov I (1993) World fresh water resources. In: Gleick Peter H (ed) Water in crisis: a guide to the world's fresh water resource. Oxford University Press, New York

United Nations-Water (2007) Coping with water scarcity. Challenge of the twenty-first century (http:// www.fao.org/nr/water/docs/escarcity)

Verpoorter C, Kutser T, Seekell DA, Tranvik LJ (2014) A global inventory of lakes based on high-resolution satellite imagery. Geophys Res Lett 41:6396-6402. doi:10.1002/2014GL060641

Wania R et al (2013) Present state of global wetland extent and wetland methane modelling: methodology of a model intercomparison project (WETCHIMP). Geosci Model Dev 6:617-641. doi:10.5194/ gmd66172013

Xiao X et al (2005) Mapping paddy rice agriculture in South and Southeast Asia using multi-temporal MODIS images. Remote Sens Environ 100:95-113

Xiao X et al (2006) Mapping paddy rice agriculture in southern China using multi-temporal MODIS images. Remote Sens Environ 95:480-492 